\title{
molecules
}

ISSN 1420-3049

http://www.mdpi.org

Full Paper

\section{Application of the Solid-Phase Julia-Lythgoe Olefination in Vitamin D Side-Chain Construction}

\author{
Jo N. D'herde and Pierre J. De Clercq * \\ Ghent University, Department of Organic Chemistry, Laboratory for Organic Synthesis, Krijgslaan \\ 281 (S4), B-9000 Gent, Belgium
}

* Author to whom correspondence should be addressed: E-mail: pierre.declercq@UGent.be

Received: 11 August 2006 / Accepted: 22 August 2006 / Published: 26 August 2006

\begin{abstract}
An example of the Julia-Lythgoe attachment of the vitamin D side chain to a solid-phase linked Inhoffen-Lythgoe diol derived CD-ring fragment is reported.
\end{abstract}

Keywords: Julia-Lythgoe olefination, solid-phase synthesis, vitamin D.

\section{Introduction}

The development of analogs of $1 \alpha, 25$-dihydroxyvitamin $\mathrm{D}_{3}\left(\mathbf{1}, 1 \alpha, 25(\mathrm{OH})_{2} \mathrm{D}_{3}\right.$, calcitriol), the hormonally active metabolite of vitamin $\mathrm{D}_{3}$ [1], is an attractive area for organic synthesis [2], ever since it was discovered that structural modifications could lead to derivatives featuring a dissociation between the classical calcemic and antiproliferative/cell-differentiating activities [3]. Analogs with low calcemic activity have potential therapeutic value [4]. The structure of calcitriol (1) consists of three parts (Figure 1), namely a central CD-ring core connected to two flexible entitiesa: the side chain at C20 and the seco-B,A-ring at C8. In view of this, the molecule is an ideal candidate for the application of combinatorial techniques to introduce molecular diversification [5]

In this context three-component vitamin $\mathrm{D}$ libraries in the solid phase have been reported by Takahashi [6]. In one approach, the central CD-ring system is linked to the solid phase, to which the two remaining portions are subsequently attached in sequence via nucleophilic carbon-carbon bond formation: the A-ring via Horner-Wittig coupling [7] followed by the side chain via $\mathrm{Cu}(\mathrm{I})$-catalysed Grignard reaction [8] (Figure 2a). 
Figure 1. Dissection of the vitamin D structure.

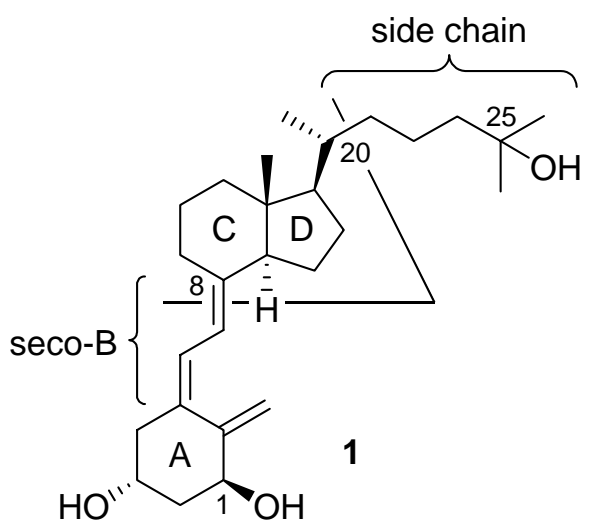

\section{Results and Discussion}

In the context of developing structural analogs of calcitriol featuring modifications in the side chain, we investigated the possibility of side-chain attachment using the recently described Julia-Lythgoe olefination on solid support [9]. In analogy with Takahashi's approach, a traceless linker is used (sulfone vs. sulfonate), the displacement of which occurs in the reductive elimination step (Figure 2b). In contrast with Takahashi's approach, however, the side chain needs to be introduced first since the vitamin D triene moiety is susceptible to reduction. As a first step towards the construction of a vitamin D library following this scenario, we describe herein the synthesis of $\mathbf{6}$ in which the C22-C23 connection is realised via Julia-Lythgoe olefination on solid support (Scheme 1).

Figure 2. Side-chain construction on solid phase: (a) Takahashi's approach; (b) this work.

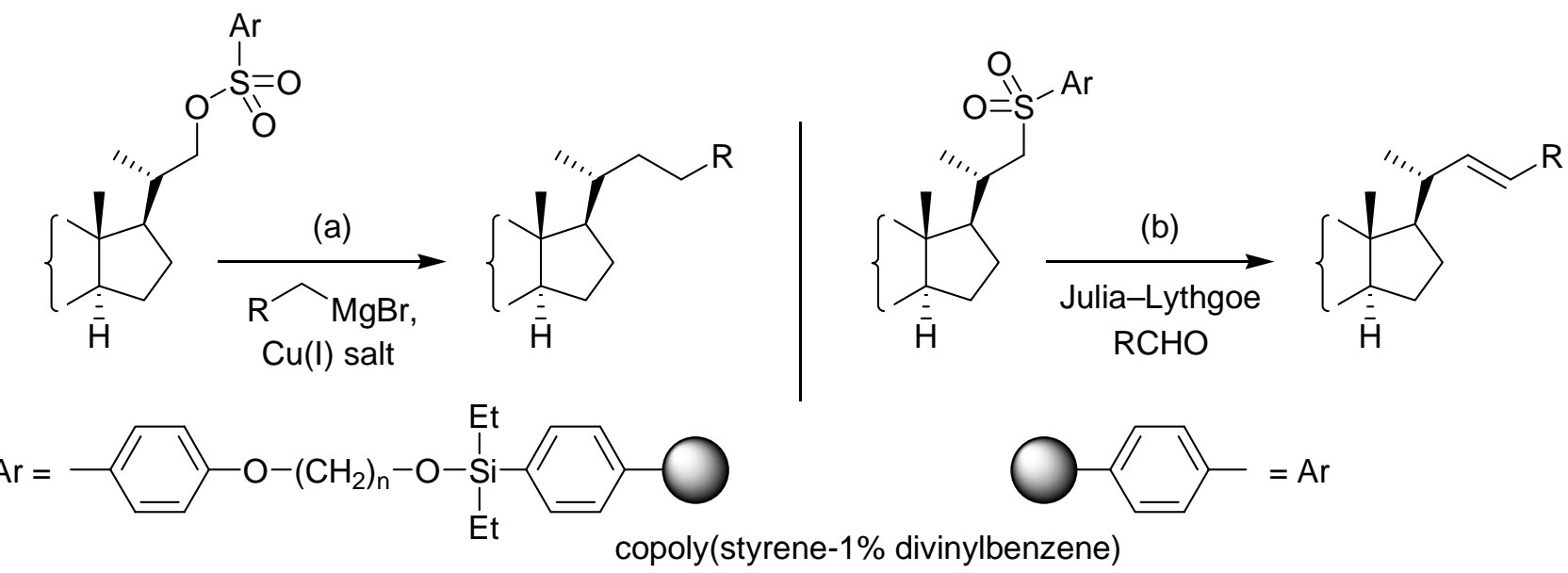

The required solid-phase linked phenylsulfone derivative $\mathbf{4}$ is obtained starting from thiophenol resin 2, which is prepared from Novabiochem ${ }^{\circledR}$ 's 4-bromopolystyrene [10]. After deprotonation of 2 (large excess of $t$-BuOK), the intermediate thiolate is isolated by filtration and subsequently treated with tosylate 3. The latter, derived from the known Inhoffen-Lythgoe diol, was obtained from vitamin $\mathrm{D}_{2}$ following an established sequence [11]. After extensive washing of the resin, the obtained sulfide is oxidised using $m$-CPBA to the corresponding sulfone 4. After deprotonation ( $n$-BuLi, toluene), the 
$\alpha$-sulfonyl carbanion is isolated and reacted with 3-methylbut-2-en-1-al, and the resulting alkoxide is directly converted into the corresponding benzoate $\mathbf{5}$. Upon subsequent reductive elimination with samarium diiodide in the presence of DMPU [12], olefin 6 was released in which the double bond possessed almost exclusively the $E$-geometry. The calculated yield for the solid-phase sequence $(\mathrm{a} \rightarrow \mathrm{f})$ is approximately $22 \%$.

Scheme 1. C22-C23 connection sequence via Julia-Lythgoe olefination on solid phase.

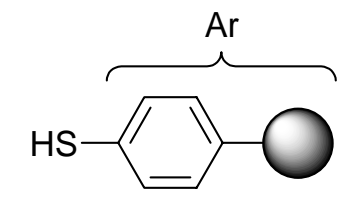

2

copoly(styrene-1\% divinylbenzene)

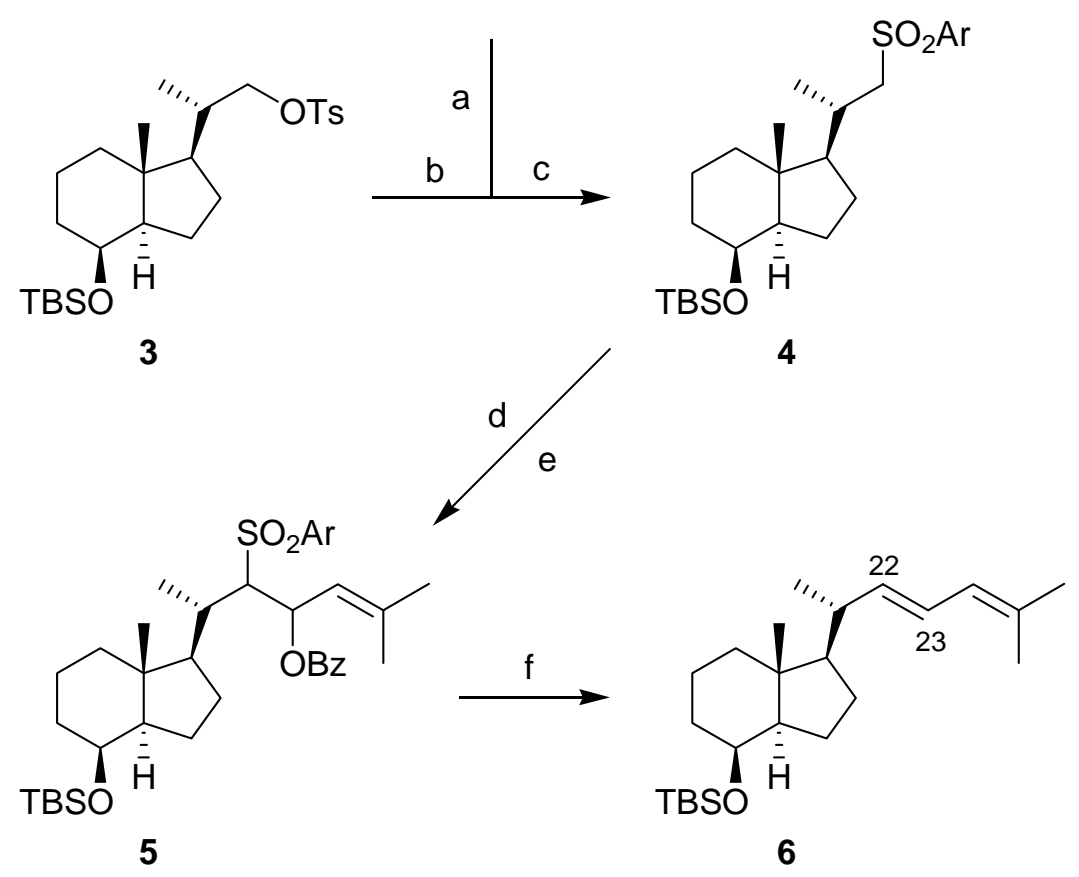

(a) $t$-BuOK, THF, DMSO; (b) THF-DMSO; (c) m-CPBA, DCM; (d) $n$-BuLi, toluene;

(e) $\mathrm{Me}_{2} \mathrm{C}=\mathrm{CHCHO}$, THF; PhCOCl; (f) $\mathrm{SmI}_{2}$, DMPU, THF.

\section{Conclusions}

The current procedure illustrates the feasibility of applying a Julia-Lythgoe olefination on solid phase to vitamin D side-chain construction. Indeed, reduction of the double bonds of $\mathbf{6}$ would produce the vitamin $\mathrm{D}_{3}$ side chain. On the other hand, adequate functionalisation of the diene could lead to the 25 -hydroxylated side chain of the active metabolite $1 \alpha, 25(\mathrm{OH})_{2} \mathrm{D}_{3}$ and certain analogs.

\section{Experimental}

\section{General}

The solid-phase syntheses were carried out in a three-neck round-bottom flask equipped with a magnetic stir bar. The wide centre neck was used as inert-gas inlet via a Teflon stopcock and for the 
addition of solids. One side neck was fitted with a septum for the addition of solvents and reagents via syringes. The other widened side neck equipped with a sealed-in sintered glass disc as filter was connected via a Teflon stopcock and connector with side tube to a round-bottom flask to collect the filtrates. Gentle suction was applied via the side tube to help filtration. Tetrahydrofuran (THF) and diethyl ether $\left(\mathrm{Et}_{2} \mathrm{O}\right)$ were distilled from benzophenone ketyl. Dichloromethane (DCM) was distilled from $\mathrm{CaH}_{2}$. Toluene was distilled from sodium. $N, N$-Dimethylformamide (DMF) and dimethyl sulfoxide (DMSO) were purchased 'anhydrous' and used as such. TLC were run on glass plates precoated with silica gel (Merck, 60F-254). Column chromatography was performed on silica gel (Merck, 230-400 mesh). IR spectra were recorded on a Perkin-Elmer series 1600 FT-IR spectrometer. ${ }^{1} \mathrm{H}-\mathrm{NMR}$ and ${ }^{13} \mathrm{C}-\mathrm{NMR}$ spectra were recorded on a Bruker AM-500 spectrometer. Hydrogen chemical shifts $\delta$ are reported in ppm relative to $\mathrm{CDCl}_{3}(7.26 \mathrm{ppm})$ as an internal reference. $J$ values are given in Hz. Carbon chemical shifts $\delta$ are reported in ppm relative to $\mathrm{CDCl}_{3}(77.16 \mathrm{ppm})$ as an internal reference. Mass spectra (EI) were recorded on a Hewlett-Packard 5898A spectrometer at $70 \mathrm{eV}$.

\section{Synthesis}

The preparation of $\mathbf{6}$ from thiophenol resin $\mathbf{2}$ involves 6 consecutive solid-phase steps $(\mathrm{a} \rightarrow \mathrm{f})$, each step involving bead swelling, reaction, filtration and thorough washing. All operations were carried out at room temperature.

\section{(a) Potassium thiolate of thiophenol resin 2}

To beads of thiophenol resin 2 (0.5 g, approx. $1.07 \mathrm{mmol})$ was added dry THF (10 mL) and dry DMSO (5 mL), and the beads were allowed to swell for $30 \mathrm{~min}$. Solid $t$-BuOK (1.44 g, $12.84 \mathrm{mmol}, 12$ eq) was added and the reaction mixture was gently stirred (50 rpm) for $90 \mathrm{~min}$. The beads were filtered off and washed twice with dry THF.

\section{(b) Substition of tosylate 3}

To the beads was again added dry THF $(10 \mathrm{~mL})$ and dry DMSO $(5 \mathrm{~mL})$, and the beads were allowed to swell. Tosylate 3 (0.97 g, $2.0 \mathrm{mmol}, 1.9 \mathrm{eq}$ ) dissolved in a minimal amount of dry THF was added dropwise and the reaction mixture was gently stirred overnight. The beads were filtered off and washed successively with 25-mL portions of THF, DMF, MeOH and DCM to give the solid-phase linked side-chain sulfide.

(c) (1S,3aR,4S,7aS)-4-(tert-Butyldimethylsilyl)oxy-7a-methyl-1-[(1S)-1-methyl-2-(phenylsulfonyl)ethyl]octahydro-1H-indene (4) [13]

To the (black) beads was added dry DCM $(15 \mathrm{~mL})$ and the beads were allowed to swell. meta-Chloroperoxybenzoic acid (m-CPBA, 77\% solution in DCM; $1.25 \mathrm{~mL}, 0.96 \mathrm{~g}, 4.28 \mathrm{mmol}, 4$ eq.) was added and the reaction mixture was gently stirred for $3.5 \mathrm{~h}$. The (white) beads were filtered off, washed with $\mathrm{MeOH}$ and DCM, and dried under vacuum to afford the corresponding resin bonded sulfone 4. 


\section{(d) $\alpha$-Sulfonyl carbanion of sulfone 4}

To the beads was added dry toluene $(11 \mathrm{~mL})$ under an inert atmosphere and the beads were allowed to swell. $n$-BuLi (2.3 M solution in hexanes; $2.33 \mathrm{~mL}, 0.34 \mathrm{~g}, 5.35 \mathrm{mmol}, 5 \mathrm{eq}$ ) was dropwise added, turning the beads yellow. The reaction mixture was gently stirred for $30 \mathrm{~min}$ and the excess reagent was removed by filtration.

(e) (1R,3aR,4S,7aR)-1-[(1S)-3-Benzoyloxy-1,5-dimethyl-2-(phenylsulfonyl)hex-4-en-1-yl]-4-(tertbutyldimethylsilyl)oxy-7a-methyloctahydro-1H-indene (5)

To the beads was added dry THF (11 mL) and 3-methylbut-2-en-1-al (0.206 mL, $0.180 \mathrm{~g}, 2.14$ mmol, 2 eq.) under an inert atmosphere and the reaction mixture was gently stirred for $5 \mathrm{~h}$. Benzoyl chloride (0.745 mL, $0.902 \mathrm{~g}, 6.42 \mathrm{mmol}, 6$ eq.) was added and the reaction mixture was gently stirred for $15 \mathrm{~h}$. The beads were filtered off, consecutively washed with $\mathrm{MeOH}, \mathrm{DMF}, \mathrm{Et}_{2} \mathrm{O}$ and DCM, and dried under vacuum to give the corresponding solid-phase linked benzoate 5: IR (KBr pellet) $v 2928$ (s), 1943 (w), 1872 (w), 1801 (w), 1720 (s, C=O stretching), 1638 (m), 1601 (m), 1491 (m), 1452 (m), 1381 (m), 1316 (m, S=O stretching), 1261 (m), 1147 (m, S=O stretching), 1116 (m), 1082 (m), 1028 (m), 973 (w), 924 (w), 836 (m), 759 (m), 697 (s), $618(\mathrm{w}), 543(\mathrm{w}) \mathrm{cm}^{-1}$.

(f) $(1 R, 3 a R, 4 S, 7 a R)-4-(t e r t-B u t y l d i m e t h y l s i l y l) o x y-1-[(1 R, 2 E)-1,5-d i m e t h y l h e x a-2,4-d i e n-1-y l]-7 a-$ methyloctahydro-1H-indene (6)

The beads were washed twice with dry THF under an inert atmosphere. $\mathrm{SmI}_{2}(0.1 \mathrm{M}$ solution in THF; $100 \mathrm{~mL}, 10 \mathrm{mmol}, 9.34$ eq.) was added, followed after $10 \mathrm{~min}$ by 1,3-dimethyl-3,4,5,6tetrahydro-2(1H)-pyrimidinone (DMPU; $3.86 \mathrm{~mL}, 4.108 \mathrm{~g}, 32.1 \mathrm{mmol}$ ), and the reaction mixture was vigorously stirred overnight. The beads were filtered off, the filtrate was poured into an aqueous solution of $\mathrm{Na}_{2} \mathrm{~S}_{2} \mathrm{O}_{3}$ and $\mathrm{NH}_{4} \mathrm{Cl}$, and the aqueous layer was extracted with $\mathrm{Et}_{2} \mathrm{O}$. The combined organic layers were washed with $\mathrm{H}_{2} \mathrm{O}$ and a saturated $\mathrm{NaCl}$ solution, dried over anhydrous $\mathrm{MgSO}_{4}$ and concentrated under reduced pressure. The residue was purified by column chromatography on silica gel (eluent: isooctane) to afford the side-chain E-olefin 6 (90 mg, $0.24 \mathrm{mmol}, 22 \%$ overall yield from 2): $R_{f}$ (isooctane/Me $\left.{ }_{2} \mathrm{CO}, 9: 1\right)$ 0.79; IR (KBr film) v 2230 (s), 2857 (s), 1472 (m), 1372 (m), 1252 (m), 1163 (m), 1094 (m), 1081 (m), 1020 (m), 960 (m), 924 (m), 870 (w), 836 (s), 774 (s), $688(\mathrm{w}) \mathrm{cm}^{-1} ;{ }^{1} \mathrm{H}$ NMR (500 MHz, $\mathrm{CDCl}_{3}$ ) $\delta 6.13(1 \mathrm{H}, \mathrm{dd}, J=15.0,10.8 \mathrm{~Hz}), 5.75(1 \mathrm{H}, \mathrm{d}, J=10.8 \mathrm{~Hz}$ ), 5.39 (1 H, dd, $J=15.0,8.7 \mathrm{~Hz}), 3.99(1 \mathrm{H}, \mathrm{m}), 2.10(1 \mathrm{H}, \mathrm{m}), 1.94(1 \mathrm{H}, \mathrm{m}), 1.81(1 \mathrm{H}, \mathrm{m}), 1.75(3 \mathrm{H}, \mathrm{s}), 1.73(3 \mathrm{H}$, s), $1.64(2 \mathrm{H}, \mathrm{m}), 1.53(1 \mathrm{H}, \mathrm{m}), 1.39-1.07$ (7 H, m), 1.02 (3 H, d, J = 6.6 Hz), 0.94 (3 H, s), 0.89 (9 H, s), 0.00 (3 H, s), -0.01 (3 H, s) ppm; ${ }^{13} \mathrm{C} \mathrm{NMR/APT} \mathrm{(125} \mathrm{MHz,} \mathrm{CDCl}_{3}$,) $\delta 138.5$ (CH), 132.3 (C), $125.3(\mathrm{CH}), 123.9(\mathrm{CH}), 69.4(\mathrm{CH}), 56.7(\mathrm{CH}), 53.0(\mathrm{CH}), 42.1(\mathrm{C}), 40.6\left(\mathrm{CH}_{2}\right), 39.7(\mathrm{CH}), 34.4$ $\left(\mathrm{CH}_{2}\right), 27.6\left(\mathrm{CH}_{2}\right), 25.7\left(\mathrm{CH}_{3}\right), 25.7\left(\mathrm{CH}_{3}\right), 23.0\left(\mathrm{CH}_{2}\right), 20.5\left(\mathrm{CH}_{3}\right), 20.5\left(\mathrm{CH}_{3}\right), 18.1(\mathrm{C}), 17.6\left(\mathrm{CH}_{2}\right)$, $13.8\left(\mathrm{CH}_{3}\right),-4.9\left(\mathrm{CH}_{3}\right),-5.4\left(\mathrm{CH}_{3}\right) \mathrm{ppm}$; MS m/z (\%) $376\left(16, \mathrm{M}^{+}\right), 361\left(1, \mathrm{M}^{+}-\mathrm{Me}\right), 319\left(16, \mathrm{M}^{+}-\right.$ t-Bu), 265 (17), 243 (10), 237 (16), 209 (9), 187 (2), 171 (2), 161 (14), 135 (67), 109 (100), 75 (99), 55 (15), 41 (15); Anal. Calcd for $\mathrm{C}_{24} \mathrm{H}_{44} \mathrm{OSi}$ : C, 76.50; H, 11.80. Found: C, 76.38; H, 11.64. 


\section{Acknowledgements}

Financial support through project BOF 01.1042.01 is gratefully acknowledged. J. D. thanks the Ghent University for an assistant position.

\section{References and Notes}

1. (a) Proceedings of the 12th Workshop on Vitamin D; Bouillon, R.; Norman, A. W.; Pasqualini, J. R., Eds.; J. Steroid Biochem. Mol. Biol. 2004, 89-90, 1-633, and the previous 11 volumes in this series; (b) Vitamin D; Feldman, D.; Glorieux, F. H.; Pike, J. W., Eds.; Academic Press: San Diego, 1997.

2. (a) Zhu, G.-D.; Okamura, W. H. Chem. Rev. 1995, 95, 1877-1952; (b) Dai, H.; Posner, G. H. Synthesis 1994, 1383-1398.

3. (a) Nagpal, S.; Na, S.; Rathnachalam, R. Endocr. Rev. 2005, 26, 662-687; (b) Bouillon, R.; Okamura, W. H.; Norman, A. W. Endocr. Rev. 1995, 16, 200-257.

4. (a) Kabat, M. M.; Radinov, R. Curr. Opin. Drug Disc. 2001, 4, 808-833; (b) Posner, G. H.; Kahraman, M. Eur. J. Org. Chem. 2000, 3889-3895.

5. (a) Cano, M.; Balasubramanian, S. Drug Future 2003, 28, 659-678; (b) Ganesan, A. Drug Discov. Today 2002, 7, 47-55; (c) Fruchtel, J. S.; Jung, G. Angew. Chem., Int. Ed. 1996, 35, 17-42.

6. (a) Hijikuro, I.; Doi, T.; Takahashi, T. J. Am. Chem. Soc. 2001, 123, 3716-3722; (b) Doi, T.; Hijikuro, I.; Takahashi, T. J. Am. Chem. Soc. 1999, 121, 6749-6750.

7. (a) Baggiolini, E. G.; Iacobelli, J. A.; Hennessy, B. M.; Batcho, A. D.; Sereno, J. F.; Uskokovic, M. R. J. Org. Chem. 1986, 51, 3098-3108; (b) Lythgoe, B.; Moran, T. A.; Nambudiry, M. E. N.; Ruston, S.; Tideswell, J.; Wright, P. W. J. Chem. Soc., Perkin Trans. 1 1978, 590-595.

8. (a) Franzen, R. G. Tetrahedron 2000, 56, 685-691; (b) Schlosser, M. Angew. Chem., Int. Ed. 1974, 13, 701-706.

9. D'herde, J. N. P.; De Clercq, P. J. Tetrahedron Lett. 2003, 44, 6657-6659.

10. Fréchet, J. M. J.; de Smet, M. D.; Farrell, M. J. Polymer 1979, 20, 675-680.

11. (a) Fernández, B.; Martinez Pérez, J. A.; Granja, J. R.; Castedo, L.; Mouriño, A. J. Org. Chem. 1992, 57, 3173-3178; (b) Mascareñas, J. L.; Mouriño, A.; Castedo, L. J. Org. Chem. 1986, 51, 1269-1272.

12. Shabangi, M.; Sealy, J. M.; Fuchs, J. R.; Flowers II, R. A. Tetrahedron Lett. 1998, 39, 4429-4432.

13. In the compound chemical name of $\mathbf{4}$ and $\mathbf{5}$ the phenylsulfonyl group, although further connected via the 4-position to the solid phase (see Scheme 1), is named as such. The ACD/I-Lab Web service (ACD/IUPAC Name Free 8.05) was used to generate the core of the chemical names.

Sample Availability: No samples available.

(c) 2006 by MDPI (http://www.mdpi.org). Reproduction is permitted for noncommercial purposes. 